\title{
Democracia electoral fraudulenta. La trashumancia electoral como estrategia para ganar elecciones locales en Colombia*
}

\author{
Javier Duque Daza (Colombia)**
}

\section{Resumen}

Este artículo analiza la trashumancia electoral, una modalidad de fraude electoral con la cual se movilizan electores de municipios que no corresponden a los padrones electorales locales. Es una de las más reiteradas y determinantes en los resultados, falseando así el proceso electoral. Este artículo es un análisis empírico de nueve elecciones consecutivas del periodo 1990-2015, de las dimensiones, tendencias y de la lógica que impera en esta modalidad. La metodología incluye el análisis de estadísticas de registro, cedulación y anulación de las inscripciones por presunción de trashumancia, la recolección de testimonios orales y escritos, y un análisis sistemático de diarios nacionales y regionales. Se concluye que, pese a la normativa al respecto y a la creación del nuevo tipo penal de fraude electoral, es muy difícil demostrar el delito y condenar a los implicados, y en muy pocas ocasiones se ha procedido a la anulación de las elecciones; finalmente, se propone para el caso colombiano la denominación de democracia electoral fraudulenta.

\section{Palabras clave}

Sistema Electoral; Elecciones; Fraude Electoral; Trashumancia Electoral; Partidos Políticos.

Fecha de recepción: mayo de 2018 • Fecha de aprobación: enero de 2019

\section{Cómo citar este artículo}

Duque Daza, Javier. (2019). Democracia electoral fraudulenta. La trashumancia electoral como estrategia para ganar elecciones locales en Colombia. Estudios Políticos (Universidad de Antioquia), 55, pp. 61-86. http://doi.org/10.17533/ udea.espo.n55a04

\footnotetext{
* Este artículo hace parte de la investigación Las urnas contaminadas, financiada por la Universidad del Valle en 2016-2018.

** Politólogo. Doctor en Ciencia Política. Profesor investigador de la Universidad del Valle, Colombia. Correo electrónico: jduqued86@hotmail.com - Orcid: https://orcid.org/0000-0001-9996-4835
} 


\title{
Fraudulent Electoral Democracy. Electoral Transhumance as a Strategy to Win Local Elections in Colombia
}

\begin{abstract}
This article analyzes electoral transhumance, a form of electoral fraud that mobilizes voters in municipalities that do not correspond to the local electoral rolls. It is one of the most repeated and decisive strategies that affect the election results; thus, distorting the electoral process. This article provides an empirical analysis of nine consecutive elections in the period 1990-2015, and takes into account the dimensions, tendencies and logic that prevails in this modality of electoral fraud. The methodology includes the analysis of registration statistics, registration and cancellation of inscriptions for presumption of transhumance, the collection of oral and written testimonies, and a systematic analysis of national and regional journals. The study concludes that, despite the regulations and the typification of a new criminal type of electoral fraud in this regard, these crimes are very difficult to prove; therefore, it is also very difficult to condemn the people involved. As a result, elections have been cancelled in very few cases associated to this crime. Finally, it is proposed to denominate the Colombian regime as a fraudulent electoral democracy.
\end{abstract}

\section{Keywords}

Electoral Systems; Elections; Electoral Fraud; Electoral Transhumance; Political Parties. 


\section{Introducción}

Las elecciones son centrales y fundamentales para la democracia, también lo son para los partidos, pues en ellas se pone en juego su acceso o permanencia en los cargos y en las curules en las corporaciones de representación. Los ciclos electorales constituyen periodos fundamentales para los partidos y los políticos, en ellos se invierte una parte sustancial de sus recursos, tiempo y esfuerzos, y entran en juego los engranajes de las organizaciones, lo que en lenguaje coloquial y periodístico se suele denominar «la maquinaria política», la cual incluye a políticos, intermediarios, círculos de confianza, equipos de asesores, operarios políticos y personal adscrito a los partidos o de allegados de los candidatos.

Los partidos se desempeñan en las arenas gubernativa, de gestión, administrativa, parlamentaria y electoral, estas son las caras partidistas (Katz y Mair, 1990, 9-13 de julio). Cada una de ellas constituyen escenarios de acción y de su desempeño depende el lugar que ocupen en el sistema político los partidos, sus unidades internas, sus líderes y sus candidatos. Aunque hay diversos tipos de partidos y sus motivaciones y orientaciones son múltiples, el escenario electoral es común a todos. Para afrontarlo implementan estrategias de agregación de votos, de tal forma que estas organizaciones siempre tienen sus ojos puestos en los electores, ya sea para mantenerlos, reproducirlos, persuadirlos o movilizarlos.

En las democracias la competencia electoral es abierta pero regulada, cada sistema electoral establece reglas que dan posibilidades de acción pero también restringen y limitan: el tipo de empadronamiento, de candidaturas y de listas, cuando se trata de cuerpos colegiados — abiertas o cerradas-; el número de candidatos a incluir en las listas; la posibilidad de candidatos de coaliciones o a través de grupos independientes con apoyo ciudadano; la barrera o umbral electoral; la fórmula de conversión de votos en escaños. Bajo el marco institucional los partidos establecen estrategias electorales: algunos apuestan a sus redes de apoyo — redes sociales o clientelares-, otros movilizan electores con base en programas y propuestas; otros apelan a liderazgos carismáticos; también se recurre a componentes identitarios de diverso tipo — religiosos, étnicos, comunidades de interés-. Hay también opciones que enfatizan en el marketing, el manejo de la imagen y de las redes sociales virtuales. 
El tipo de vínculos que se establecen entre partidos y electores depende de las características de la democracia, así como de su grado de desarrollo. El desempeño de los partidos en la persecución de sus fines difiere entre países (Basedau y Stroh, 2008) y esta diversidad está en función de los grados de consolidación de las democracias. En las democracias de mayor calidad los nexos de los partidos con la población pasan por la existencia de partidos institucionalizados y estables que son regulados por normas que favorecen los procesos internos de control de las candidaturas, limitan el fraccionalismo interno y la fragmentación en el sistema de partidos; contienen las aventuras personalistas; establecen barreras al ingreso de dineros ilícitos; controlan el censo electoral y constriñen su manipulación. Los partidos dependen de procesos instituidos de selección de candidatos, con la figura de la membresía o la búsqueda de adherentes con base en ofertas de políticas, de programas y de acciones gubernativas y legislativas que tienen coberturas y orientaciones colectivas. Son los partidos los que adelantan las campañas y la adhesión de los ciudadanos, además sus votos no están en función de intercambios inmediatos o de ofertas particularistas o personales, tampoco están mediadas por la existencia de redes de clientelas en torno a patronos o políticos individuales. Asimismo, las agencias de control interinstitucional son efectivas en la prevención de prácticas o modos de obrar políticos basados en la corrupción y la manipulación del proceso electoral.

Por contraste, en democracias de baja calidad es frecuente la debilidad de la institucionalización partidista. Las candidaturas no siempre son reguladas con base en reglas y existen formas de ascenso basadas en iniciativas personales o de facciones con poder económico y estructuras de apoyos con base en los cuales se insertan en los partidos o simplemente obtienen el aval de estas, a las cuales les interesa agregar apoyos, aun sin tener certeza sobre la procedencia de quienes lo solicitan. La búsqueda y consecución de electores no depende de estrategias organizacionales estructuradas de carácter partidista, sea que estén basadas en ofertas programáticas, o de promoción de imagen y de marketing o de movilización de los afiliados y simpatizantes. Imperan vínculos clientelares de las diversas facciones y jefes políticos, o se recurre a la compra del voto en contextos de laxa regulación legal, se acude a las redes de amigos y allegados, y de patrocinadores privados de las campañas motivados por la expectativa de obtención de ventajas si el candidato que apoyan tiene éxito (Duque, 2005; Yardimci-Geyikci, 2013). Asimismo, los partidos y los políticos no tienen plena autonomía respecto de otros actores que inciden en su desempeño y en la forma como compiten. 
Las reglas electorales inciden en el desempeño competitivo de los partidos. Como se ha establecido en la literatura comparada, hay ciertas reglas electorales que favorecen la política personalista respecto a la política partidista: las listas abiertas con voto preferente incentivan una mayor competencia intrapartidista y permiten que en los partidos convivan políticos que trabajan por mantener sus feudos electorales sin que el partido cuente con adherentes o miembros estables que generan mayores gastos en las campañas (Cox y Thies, 2000). A diferencia del sistema de listas únicas, cerradas y controladas por la dirigencia partidista, se establece una carrera personal por posiciones, por acceder y mantenerse en los cargos y para lograrlo se recurre a fuentes diversas de financiación en elecciones cada vez más costosas, en contextos con presencia de un crimen organizado muy fuerte hay casos de financiación política ilegal o se recurre a formas directas de transacción para intentar asegurar la votación requerida. Esto es más frecuente si hay normas laxas o precarios controles de la financiación de las campañas. En tal sentido, la competencia, moldeada en parte por las instituciones, incide en las estrategias de los partidos en cuanto al fraude electoral se refiere.

En estas democracias de baja calidad o deficitarias, en las que predominan partidos conformados por lo que se denominan políticos de negocios (Della Porta, 1996), algunas estrategias de agregación de electores colindan con la ilegalidad o son abiertamente ilegales. Se transforman las organizaciones en agregaciones conflictivas de jefes locales o caciques políticos cuyos intereses pasan más por los negocios que por la política, y se recurre al fraude y a la manipulación para acceder o mantenerse en los cargos y en las posiciones de influencia y de poder. En ese tipo de democracias tienden a predominar los partidos fraccionados, que en elecciones locales o regionales actúan como una constelación de grupos de poder faccional con maquinarias locales que compiten por recursos y posiciones; muchas de ellas operan como grupos de clientela que con frecuencia acuden a la corrupción electoral como medio de acción. El sistema de partidos se transforma en «un sistema de socialización para lo ilícito».

En el marco de estas coordenadas, este artículo analiza la trashumancia electoral, una de las estrategias usadas para lo ilícito, para ganar elecciones de forma fraudulenta, que consiste en una acción mediante la cual los políticos y sus organizaciones locales y los operarios políticos movilizan electores de otros municipios del mismo o de otro departamento mediante la compra masiva de votos, para que apoyen el día de las elecciones al candidato que 
les indiquen, desplazándose desde su lugar de residencia al municipio que les señale.

Esta forma de fraude electoral es una de las más reiteradas y en muchas localidades ha sido determinante de los resultados, falseando el proceso electoral. Varían sus denominaciones según los países, pero está presente en gran parte de América Latina: en Perú se denominan electores golondrinos; en México, turismo electoral; en Guatemala y Chile, acarreo electoral; en Bolivia, traslado fraudulento de electores; en Honduras, traslados domiciliarios irregulares; en El Salvador, traslado de votantes; en Panamá y Colombia, trashumancia electoral.

Este estudio es una primera aproximación a la temática, poco explorada hasta ahora en Colombia. El análisis de nueve elecciones consecutivas permite visualizar el fenómeno en su conjunto, las tendencias y sus expresiones más significativas. La metodología del trabajo incluyó el análisis de las estadísticas de registro, cedulación y anulación de las inscripciones por presunción de trashumancia, y la recolección de testimonios escritos sobre el funcionamiento del entramado de la movilización de electores, complementado con testimonios orales de varios líderes locales. También se hizo un análisis

[ 66 ] sistemático de diarios nacionales y regionales que permitieron reconstruir algunos eventos especiales.

Es un análisis de caso en una democracia de baja calidad en la que los partidos son débilmente institucionalizados y altamente personalizados; en la que predominan las facciones y las estructuras locales de poder con facciones basadas en clientelas; en la que la competencia partidista y la movilización de electores se basa mayoritariamente en la distribución de incentivos selectivos con débil presencia de incentivos colectivos, de identidad o de ideología; en la que la regulación estatal de las campañas es débil y la organización electoral ha sido permeada por la corrupción en el ámbito local (León, 2011; Duque, 2018; Pachón, 2018).

\section{Trashumancia electoral como modalidad de fraude}

Uno de los componentes básicos que incluyen todas las definiciones — minimalistas o maximalistas - de democracia es la presencia de elecciones periódicas, universales, libres, justas y limpias. Este último atributo supone, a su vez, unos mínimos constitutivos sobre los cuales hay cierto consenso que se puede sintetizar en siete aspectos: un censo o padrón electoral confiable 
y no manipulable; que todos los adultos posean un documento mediante la cual puedan ejercer el derecho al voto; que haya autoridades electorales autónomas; que se vigile de forma efectiva el proceso electoral; que haya información oportuna sobre el resultado de las elecciones; que exista un sistema de conteo y cómputo confiable; que se tipifiquen y penalicen los delitos electorales para inhibir la comisión de fraudes (Crespo, 2013).

La violación de uno o más de estos atributos mínimos afecta la limpieza de las elecciones y da pie al fraude electoral, definido como la vulneración o manipulación de una norma o procedimiento legal que pretende afectar o afecta el resultado final en las elecciones. Más sucintamente: «constituye el recurso a acciones clandestinas para alterar los resultados electorales» (Lehoucq, 2007, p. 2). No es suficiente que se presenten anomalías o irregularidades para considerar que hay fraude electoral, elecciones contaminadas e injustas, se requiere de cierta intensidad y regularidad en la manipulación y de la violación de las normas, por cuanto hasta en las democracias consolidadas pueden darse algunas eventuales irregularidades. En este sentido, es útil recordar la distinción que propone Andreas Schedler (2013), quien diferencia el fraude cuando hay interferencia y manipulación ilegal del proceso electoral de forma extendida y sistemática, o incluso menos intensa pero suficientemente seria para afectar los resultados de las irregularidades, y cuando hay acciones desviación de las reglas formales, pero no son extendidas ni sistemáticas ni afectan los resultados finales.

A la luz de esta distinción, la trashumancia electoral es una forma de fraude que obstaculiza la participación, afecta la autonomía individual y la libertad de elegir, distorsiona y manipula la transparencia del proceso electoral y los resultados de las elecciones al permitir que personas sin vínculos sociales estables y sin permanencia o residencia real en las comunidades definan o incidan en la escogencia de quién gobernará un municipio, departamento, estado o provincia, y quienes conformarán sus cuerpos colegiados y tomarán las decisiones a nombre de la sociedad local.

En América Latina hay doce países que han incluido en sus códigos electorales o penales la trashumancia electoral y han establecido sanciones, incluso castigos de prisión. Esta movilidad ilegal de electores ha sido revelada especialmente en las dos últimas décadas por denuncias de medios de comunicación, por veedurías locales e internacionales, por organizaciones sociales o por los propios partidos y candidatos que se han visto afectados de 
forma negativa o han perdido elecciones por votantes importados. Esta práctica ilegal constituye una de las dimensiones de los déficits de la democracia electoral en América Latina, lo cual implica que quienes gobiernan no siempre son los que cuentan con el aval de las mayorías electorales y que pueden ser elegidos por mayorías fabricadas y la adulteración de los resultados.

Cuadro 1. Inclusión de la trashumancia electoral como delito en América Latina.

\begin{tabular}{|c|c|c|}
\hline País & Descripción & Normas legales \\
\hline Colombia & $\begin{array}{l}\text { El que por cualquier medio indebido logre que } \\
\text { personas habilitadas para votar inscriban documento } \\
\text { o cédula de ciudadanía en una localidad, municipio } \\
\text { o distrito diferente a aquel donde residan con el } \\
\text { propósito de obtener ventaja de ello. }\end{array}$ & $\begin{array}{l}\text { Ley } 599 \text { de } 2000 . \\
\text { Código Penal }\end{array}$ \\
\hline México & $\begin{array}{l}\text { Alterar o participar en la alteración del Registro } \\
\text { Federal de Electores o que movilicen a personas para } \\
\text { cualquier contraprestación o dádiva para que den } \\
\text { datos falsos ante el Instituto Nacional Electoral. }\end{array}$ & $\begin{array}{l}\text { Artículo 13, } \\
\text { Ley General en } \\
\text { Materia de Delitos } \\
\text { Electorales de } 2014\end{array}$ \\
\hline Perú & $\begin{array}{l}\text { Cambio ficticio de domicilio de un grupo de electores } \\
\text { en complicidad con algún agente instigador. Que } \\
\text { la persona que reside en un distrito modifique su } \\
\text { domicilio para ser incluido en el padrón electoral de } \\
\text { otro distrito. }\end{array}$ & Ley 29287 de 2008 \\
\hline Argentina & $\begin{array}{l}\text { Inscripciones múltiples o con documentos } \\
\text { adulterados, informar sobre domicilio falso, retención } \\
\text { indebida de documentos cívicos. }\end{array}$ & $\begin{array}{l}\text { Código Electoral } \\
\text { Nacional de } 1983\end{array}$ \\
\hline Brasil & $\begin{array}{l}\text { Cuando los votantes declaran por escrito falsamente } \\
\text { ser residentes en el municipio y no pueden demostrar } \\
\text { que tengan lazos con la localidad. }\end{array}$ & $\begin{array}{l}\text { Artículo 350, Código } \\
\text { Eleitoral, Lei } 4737 \\
\text { de } 1965\end{array}$ \\
\hline Chile & $\begin{array}{l}\text { Acarrero de electores cuando se declara un vínculo } \\
\text { objetivo y se entrega un domicilio electoral } \\
\text { diferente a los permitidos en la Ley. Implica abultar } \\
\text { artificialmente el padrón electoral e intervenir en el } \\
\text { resultado de las elecciones. }\end{array}$ & Ley 18556 de 1986 \\
\hline Guatemala & $\begin{array}{l}\text { Acarreo electoral cuando un candidato moviliza } \\
\text { a personas de un municipio a otro para que voten } \\
\text { por él. Las personas «acarreadas» mienten sobre su } \\
\text { residencia electoral para votar en otro municipio. }\end{array}$ & $\begin{array}{l}\text { Artículo 27B, Código } \\
\text { Penal de } 2016\end{array}$ \\
\hline Honduras & $\begin{array}{l}\text { Inscripción y traslados domiciliarios en municipios } \\
\text { donde no residen los solicitantes para favorecer con } \\
\text { el voto a candidatos a cargos de elección. }\end{array}$ & $\begin{array}{l}\text { Decreto } 044 \text { de } \\
2004\end{array}$ \\
\hline
\end{tabular}


Cuadro 1. (Continuación)

\begin{tabular}{|l|l|l|}
\hline Bolivia & $\begin{array}{l}\text { La autoridad o cualquier persona que promueva, } \\
\text { incite o ejecute el traslado masivo de personas con la } \\
\text { finalidad de su inscripción o sufragio en lugar distinto } \\
\text { al de su domicilio. }\end{array}$ & $\begin{array}{l}\text { Artículo 202, Ley } \\
\text { 2232 de 2001 }\end{array}$ \\
\hline $\begin{array}{l}\text { República } \\
\text { Dominicana }\end{array}$ & $\begin{array}{l}\text { La inscripción o traslado de electores a una } \\
\text { demarcación electoral en la cual no tienen residencia, } \\
\text { con el propósito de influir ilegítimamente en las } \\
\text { votaciones de esa localidad. }\end{array}$ & $\begin{array}{l}\text { Artículo 52, Ley 55 } \\
\text { de Registro Electoral } \\
\text { de 1970 }\end{array}$ \\
\hline El Salvador & $\begin{array}{l}\text { Adulterar el registro electoral modificando los } \\
\text { datos de las personas habilitadas para votar en una } \\
\text { circunscripción territorial diferente de la que residen. }\end{array}$ & $\begin{array}{l}\text { Artículo 295 del } \\
\text { Código Penal de } \\
1997\end{array}$ \\
\hline Panamá & $\begin{array}{l}\text { Empadronarse dolosamente en el censo electoral o } \\
\text { inscribir en el Registro Electoral en un corregimiento } \\
\text { distinto al de su residencia. }\end{array}$ & $\begin{array}{l}\text { Código Electoral de } \\
2017\end{array}$ \\
\hline
\end{tabular}

Fuente: elaboración propia.

Al detectarse la trashumancia electoral desde 1988 la legislación empezó a adecuarse de forma lenta. Con la Ley 6 de 1990 se estableció que solo se podría votar en el lugar en que apareciera la cédula de ciudadanía registrada, conforme al censo electoral. Posteriormente, en la Constitución Política de 1991, el artículo 316 estableció de forma escueta que en las votaciones solo podrán participar los ciudadanos residentes en el respectivo municipio. Un desarrollo parcial de la Constitución se dio con la Ley 163 de 1994, la cual determinó que cuando se compruebe que el inscrito no reside en el respectivo municipio el Consejo Nacional Electoral (CNE) declarará sin efecto la inscripción. Esta norma abrió la puerta para anular las inscripciones que se hicieran de forma irregular.

La trashumancia electoral venía creciendo y de forma recurrente la prensa daba cuenta del nivel de organización y de las dimensiones que tenía. Después de muchas denuncias y de reiteradas demandas de candidatos y partidos ante el CNE se tipificó la trashumancia o trasteo de votos como un delito. En la Ley 599 de 2000 se estableció la figura del fraude en la inscripción de cédulas cuando de forma indebida se inscribiera la cédula en una localidad, municipio o distrito diferente a aquel donde se haya nacido o se resida, con el propósito de obtener ventaja en elección popular (artículo 389). Por su parte, la Corte Constitucional en su Sentencia T-135 de 2000 determinó que constituía una actuación irregular que debía ser controlada 
por el CNE, el cual debe velar por el desarrollo de las elecciones con plenas garantías. Como consecuencia, el CNE emitió la Resolución 0215 de 2007 en la que estableció el procedimiento para dejar sin efecto las inscripciones de cédulas realizadas de forma irregular.

\section{El entramado de la trashumancia electoral}

En las últimas décadas los partidos, el sistema de partidos y sus estrategias electorales han presentado cambios, así como el incremento de prácticas fraudulentas, entre las cuales sobresale la trashumancia electoral. La mayoría de los partidos se han visto involucrados en este tipo de asociaciones para lo ilícito en el ámbito local.

En las últimas cuatro décadas el sistema de partidos en Colombia transitó de un bipartidismo con división interna y gran autonomía de las facciones (1974-1990), a un multipartidismo atomizado, en el que hubo 43 partidos con representación en el Congreso (1991-2002) y a un multipartidismo atenuado con 14 partidos estabilizados (2003-2015). En todos los periodos los partidos se han caracterizado por la alta personalización y el fraccionalismo, estimulados por las reglas electorales que incentivan la búsqueda individual

[ 70 ] de acceso a los cargos de elección.

En las dos últimas décadas han sobrevivido los tradicionales partidos Liberal y Conservador y las organizaciones políticas comunitarias indígenas: Autoridades Indígenas de Colombia (AICO) y la Alianza Social Indígena (ASI) —que desde 2003 se cambió a Alianza Social Independiente-. Además de los numerosos partidos efímeros que sucumbieron en poco tiempo, algunos lograron estabilizarse en la última década, como sucedió con Cambio Radical —surgido en 1998-, el Partido Social de Unidad Nacional —creado en 2005-; el Polo Democrático Alternativo — alianza de partidos de izquierda creada en 2005—; la Alianza Verde —creado en 2013, antes Ilamado Opción Centro y Partido Verde_-; Opción Ciudadana —creado en 2009, antes llamado Convergencia Ciudadana y Partido de Integración Nacional—; y el partido comunitario-religioso Movimiento de Renovación Absoluta (MIRA) — creado en 2000—. También hay dos partidos regionales: el Movimiento de Integración Regional y Por un Huila Mejor, y un partido de reciente creación, el Centro Democrático —creado en 2013—.

El repertorio de las estrategias electorales de los partidos políticos colombianos incluye algunas que son legales, como las que recurren al 
marketing, a la proyección de la imagen de los candidatos, a la presencia de liderazgos con capacidad de movilización, a la persuasión que apela a programas y a propuestas ideológicas, o las que alimentan sus huestes de electores fieles por su procedencia religiosa o étnica. También hay estrategias que se mueven en el límite de lo ilegal y lo legal, como el clientelismo, y otras que son abiertamente ilegales e incluyen prácticas de compra de votos, ya sea a cambio de dinero o de bienes y servicios.

Hay una larga tradición de clientelismo entre los partidos Liberal y Conservador, así como en los partidos que surgieron por escisiones de estos y posteriores reagrupaciones de políticos, como Cambio Radical, Partido Social de Unidad Nacional, Opción Ciudadana y Centro Democrático. ${ }^{1}$ AICO y el MIRA apelan a electorados comunitarios e identitarios, aunque parcialmente la ASI también, convertido recientemente en una especie de agencia para expedir avales a muchos candidatos que hacen política estilo free lance. ${ }^{2}$ Igual sucedió con decenas de movimientos y partidos que compitieron en una o dos elecciones y desaparecieron. Según los reportes periodísticos, los datos de las entidades estatales y las decisiones judiciales que han involucrado a políticos y operarios políticos locales, de estas prácticas solo se excluyen la izquierda del PDA, la Alianza Verde, el MIRA y AICO.

Junto a los repertorios de estrategias hay también una diversidad de prácticas de fraude electoral, sobre las cuales han surgido diversas expresiones como montar jurados —reemplazar jurados o imponerlos para que manipulen los tarjetones, el registro y el conteo de votos—; operación canguro — pasar votos de un candidato a otro, o votos en blanco o nulos a un candidato-; carrusel electoral —votar en más de una ocasión o con tarjetones premarcados y controlados-; sustitución de muertos — personas fallecidas que aparecen votando-; urna embarazada — en las urnas se introducen tarjetones ya

\footnotetext{
${ }^{1}$ Sobre el clientelismo en este periodo hay un número significativo de estudios e investigaciones (Leal y Dávila, 1990; Duarte, 1994; Martz, 1997; Gutiérrez, 1998; Rubio, 2003; Cante, 2011; León, 2011).

${ }^{2}$ Las listas únicas con voto preferente con débil regulación interna se combinan en Colombia con cierta laxitud en las exigencias para conformar organizaciones, movimientos o partidos políticos para la presentación de candidaturas y la opción de las candidaturas independientes a través de firmas, por lo que se puede prescindir de los partidos. Los candidatos actúan en un contexto de muy poca regulación efectiva, de forma autónoma y autogestionada. Basta tener dinero o respaldo económico para ser candidato. Se requiere reunir cincuenta mil firmas para presentarse como independiente. Los partidos pueden avalar candidatos sin mayores requerimientos legales y en muchos casos se conceden avales con el fin de mantener equilibrios regionales de poder o solo para agregar nuevos políticos.
} 
marcados con anticipación-; endosamiento de electores — compra colectiva de votos para un tercero-; y la trashumancia electoral.

Gráfica 1. Componentes del entramado de la trashumancia electoral.

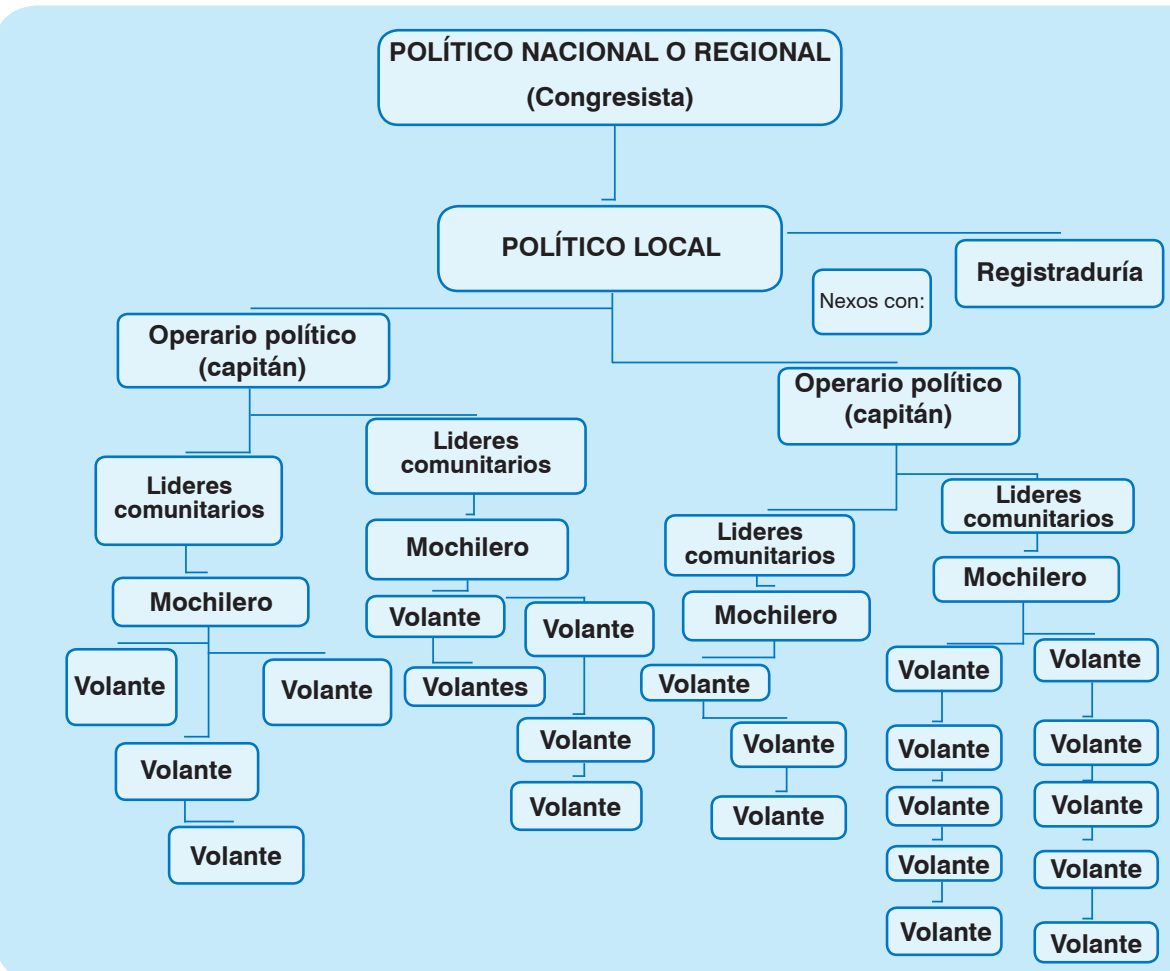

Fuente: elaboración propia.

La trashumancia electoral es una de las prácticas más recurrentes y en muchos casos resulta determinante en los resultados, especialmente en pequeños municipios y en elecciones de alcaldes, aunque también se practica para Concejos, Asambleas y Gobernaciones. Su entramado incluye a los políticos postulados a la elección o a quienes financian o respaldan a estos; a los operarios políticos integrantes de las redes del político en cuestión, llamados en algunas partes capitanes; a los líderes comunitarios; a quienes manejan el dinero o mochileros; y a los electores. En algunos casos se incorpora a la trama el registrador municipal o a algunos funcionarios de la Registraduría que hacen posible la consumación del fraude. 
En los casos más básicos la relación puede ser cuasidirecta entre el candidato y los votantes, con la intermediación de algún allegado, un familiar o alguien contratado para tal efecto, intermediada por líderes comunitarios. En otros casos en los que se mueven cientos o hasta miles de votantes foráneos se conforma una red ilícita más compleja, todo un concierto para lo ilícito.

$\square$ Los políticos locales. Candidatos a elección de alcaldes o gobernadores, o al Concejo Municipal o a la Asamblea Departamental. En la mayoría de los partidos los políticos regionales actúan como políticos de negocios, para ellos la política es una empresa: hay que invertir, procurar ganar y obtener beneficios materiales y de estatus del cargo al que se accede. Más que en estructuras organizativas consolidadas en las que se gestan liderazgos a través de procesos y caminos pautados, y de carreras construidas a través de incentivos y de méritos por atributos y capacidades de conducción y de organización, las carreras políticas se construyen de forma individual, con una gran autonomía. Son el producto de la iniciativa individual, de la capacidad de movilización, de construcción de redes de apoyo —económicas, logísticas y electorales-, de las habilidades de los políticos para competir y persuadir a segmentos de la sociedad. Políticos locales que conforman facciones que operan como pequeñas maquinarias electorales.

Como en poblados pequeños una elección puede definirse por pocos votos, traer, trasladar y trastear electores de municipios aledaños puede resultar definitivo para asegurarse la elección. ${ }^{3}$ Además de las redes clientelares, los candidatos movilizan electores con base en sus propios recursos o de allegados con expectativas e intereses en su triunfo, o con préstamos — una parte se compensa con lo que les paga el Estado por retribución de votos obtenidos-, o con aportes de empresarios de sectores de la economía legal e ilegal; en otros casos los financiadores son congresistas —-senadores o representantes a la Cámara - que han recibido —y esperan seguir recibiendo- el aporte de los votos del político local en sus respectivas elecciones y que desempeñan el papel de patronos financiadores. Los costos de este tipo de campañas son muy elevados pues son, básicamente, compras masivas de votos que incluyen gastos adicionales por el pago a otros actores de la trama, entre ellos, los registradores locales o funcionarios de las registradurías locales.

\footnotetext{
${ }^{3}$ De los 1102 municipios, $119(10,6 \%)$ tienen menos de cien mil habitantes y $872(77,7 \%)$ tiene menos de treinta mil habitantes.
} 
Los operarios políticos locales. Varios testimonios describen a estos personajes que organizan la trashumancia electoral y se encargan de contactar a otros para que consigan personas dispuestas a vender su voto y desplazarse a otro poblado. Suele denominarse el capitán y hace parte del círculo de allegados y de confianza del político, quien le paga para mantener una clientela cautiva, para que haga proselitismo y movilice electores. En algunos casos lo posesiona en un cargo público o le hace favores a sus familiares. ${ }^{4}$

Los líderes comunitarios. Muchos líderes comunitarios manejan los votos de su núcleo familiar, de sus vecinos, de organizaciones comunitarias, de clubes, a veces de varias manzanas de su barrio. En los casos de mayor experiencia y consolidación operan como pequeños empresarios electorales que compran votos o logran electores como respaldo a sus acciones de intermediación y liderazgo en sus barrios o zonas de influencia, y luego los endosan o transfieren a un candidato a cambio de dinero, bienes o favores especiales para él o sus familiares. En el caso de la trashumancia, ellos obtienen una parte significativa del total de dinero que invierten los políticos en esta estrategia, la cual oscila entre 20 y $30 \%$ del total de la operación. Primero preparan la movilización de electores, por lo que reciben una parte del pago, después los llevan a votar y les hacen el pago de la otra mitad.

Estos «líderes» pueden estar inmersos en redes de clientela y trabajar para un político, o pueden ser «agentes libres» que reúnen votantes y acuerdan los pagos para luego negociar con el mejor postor ofreciendo endosar «sus votos». Un político reconocido declaró que a su oficina se presentaban líderes comunitarios y presidentes de Juntas de Acción Comunal a ofrecer «sus electores» a cambio de cifras millonarias. Incluso algunos concejales municipales condicionaban su apoyo y «endoso electoral» a cambio de altas sumas, y funcionaban en la práctica como candidatos falsos con pocas opciones de ganar, pero con electores para vender (Semana, 2009, noviembre 21).

Los mochileros. También entran en juego quienes llevan, cargan y distribuyen el dinero, en algunos departamentos los llaman mochileros. Concentran los votos en los barrios, tienen a su cargo a personas a quienes les pagan para que «acarreen» votantes, con cuotas que oscilan entre 10 y 50 votos. Administran el dinero en dos tiempos: cuando comprometen el voto

\footnotetext{
${ }^{4}$ Puede verse una descripción más amplia en El Heraldo (2015, septiembre 20). Varios testimonios de integrantes de facciones partidistas contribuyeron a reconstruir este entramado.
} 
— se toma el registro de la residencia y el número de la cédula - y cuando hacen el pago después de que voten — para lo cual exigen el certificado electoral y luego verifican puesto por puesto los resultados-. Responden a los capitanes, que coordinan toda la operación y reciben el monto final del dinero, descontando lo que se paga a los líderes comunitarios y a los propios mochileros.

Uno de estos «mochileros» aceptó una entrevista para un diario en Barranquilla, una de las ciudades con mayor trashumancia electoral. Así describió su labor en las elecciones:

Mochilero tradicional es alguien de mucha confianza del candidato, razón por la que este le cumple «a ojo cerrado» con el pago de la cantidad de votos negociados, que por lo general son entre 300 y 500 . Actualmente se usa un talonario de recibos de caja menor en el que diligencian los datos del votante, la cantidad de dinero que se le paga y su huella dactilar. Se le da una copia y uno se queda con el original, llevamos todos los volantes al coordinador electoral —capitán-o al mismo candidato y ellos verifican que la huella corresponda con los datos de la persona a la que se le pagó, para esto cuentan con la base de datos de huellas, pues la corrupción viene desde las autoridades que dan este tipo de información. [...] Cada candidato tiene sus sitios de zonificación y las zonas donde potencializa su votación a través de nosotros. De esta manera se le facilita a los candidatos el control del número de votos que compran y esperan sacar en cada puesto y mesa de votación. Es una «obligación cuidarse» entre ellos porque los coordinadores o el mismo candidato para el que trabajan los presionan para que «los votos se vean reflejados» en los sitios donde zonificaron y movilizaron electores (Sierra, 2013, diciembre 22).

Los votantes. Esta trama no funciona si no hay personas dispuestas a vender su voto o a cambiarlo por algunos bienes de uso y consumo. Las personas tratan de optimizar su voto y reciben el transporte para ir a inscribir su cédula con la comida incluida, les adelantan la mitad del dinero y el día de las elecciones los trasladan de nuevo, y después de que voten les pagan la otra mitad. En algunas regiones esta movilización ilegal va acompañada de la compra del voto a cambio de bultos de cemento o ladrillos y otros elementos utilizados para la reparación o construcción de viviendas, también les entregan mercados, medicamentos y útiles escolares para sus hijos. 
Como hay una alta abstención, la creciente competencia y el flujo de grandes sumas de dinero juegan a favor de los electores que venden el voto. El resultado son elecciones cada vez más costosas, mayor inversión en campañas e incremento de la corrupción en la gestión local, pues los políticos de negocios procuran recuperar su inversión y obtener ganancias con su elección.

Los cómplices dentro de la organización electoral. Los registradores públicos locales y algunos funcionarios de las registradurías desempeñan un papel significativo, pues facilitan la inscripción irregular de cédulas o su falsificación. Así lo indica una pequeña revisión de registros de noticias al respecto: en 1994 fueron investigados 174 de los 1024 registradores municipales (Semana, 1994, octubre 31). En las elecciones de 1998 la organización electoral acusó a los políticos de corromper a los funcionarios en muchas ciudades para que actuaran a su favor mediante la manipulación y el fraude. El registrador nacional hizo una solicitud inusual a los partidos y dirigentes políticos: «no me corrompan a los funcionarios» (Pérez, 1998, mayo 22). En 2000 la Fiscalía Seccional de Cartagena profirió medida de aseguramiento a cuatro registradores municipales, dos notarios y una registradora de instrumentos públicos por manipular y falsear los resultados

y por fraude procesal (Llanos, 2001, abril 17). En 2002 destituyeron en una semana a siete registradores municipales, sobre los cuales recaían sospechas de alteración del proceso electoral (El Tiempo, 2002, abril 13). Antes de las elecciones de 2007, para garantizar la transparencia electoral y como medida preventiva, el registrador nacional ordenó el traslado de 47 registradores departamentales y 210 registradores municipales en distintas regiones del país (Caracol Radio, 2007, septiembre 3).

En el preámbulo de las elecciones de 2011 el presidente del Senado señaló en uno de los debates que «había muchos registradores correctos, pero también muchos con influencia política o con dinero y se prestan para torcer los resultados de la democracia». La manipulación por parte de funcionarios de la Registraduría condujo a que 42 registradores municipales fueran indagados preliminarmente y 11 fueran investigados por fraude en inscripción de cédulas y parcialidad (El Tiempo, 2011, octubre 4). En 2015 hubo varios casos: en La Guajira fue desarticulada una organización delincuencial integrada por el Registrador del municipio de Albania, dos secretarias municipales y políticos locales; en Sucre detuvieron a los 
registradores de los municipios de Ovejas y Sincelejo acusados de participar en inscripción irregular de cédulas; en San Fernando, Bolívar, detuvieron a un aspirante a la Alcaldía, dos al Concejo Municipal y tres funcionarios públicos acusados de corrupción al sufragante y fraude en inscripción de cédulas. El registrador del municipio de Atrato, Chocó, fue declarado responsable de inscribir fraudulenta de cédulas de personas que ni siquiera conocían el municipio. La Fiscalía capturó a la registradora de Puerto Colombia, Atlántico, quien suplantó ilegalmente a setecientas personas. También fue detenido registrador de Lórica, Córdoba, acusado de expedir cédulas falsas a ciudadanos venezolanos. También fue detenido el registrador de San Roque, Antioquia, por pertenecer a una red de corrupción que cobraba dinero por expedir cédulas falsas (Semana, 2015, octubre 22a; Fiscalía, 2015, octubre 14; 2015, diciembre 2; El Tiempo, 2015, octubre 8; El Universal, 2015, octubre 23).

\section{Votantes foráneos y sus dimensiones}

La trashumancia electoral ha sido una estrategia muy recurrente y extendida en el país. Se puede hacer una aproximación a sus dimensiones de tres formas: a) con base en el número de departamentos y municipios en donde se han dado anulaciones de inscripciones irregulares de cédulas; b) con base en las cifras absolutas de la anulación de inscripciones de cédulas por realizarse en lugares diferente al de la residencia de la persona; y c) con la ponderación de estas anulaciones respecto al total de inscripciones en cada elección. La anulación de inscripción de cédulas se realiza a través del cruce de las cédulas inscritas con cuatro bases de datos en las que figuran las cédulas y el lugar de residencia de las personas: El Sistema de Identificación de Potenciales Beneficiarios de Programas Sociales (Sisben); la Base de Datos Única del Sistema de Seguridad Social del Fondo de Solidaridad y Garantía (Fosyga) del Ministerio de Salud; la base de datos de los beneficiarios que acompaña a la Agencia Nacional para la Superación de la Pobreza Extrema; y El registro de la Unidad de Víctimas.

Como se observa en la tabla 1, en las dos décadas que cubre el periodo 1994-2015 el reporte de departamentos y municipios en donde se anularon inscripciones de cédulas aumentó. En los 32 departamentos esta práctica ha sido recurrente, solo se excluyen los que están ubicados lejos del centro del país, en las selvas y llanuras del oriente, y que están muy aislados y tienen poca población: Guainía, Vichada, Vaupés y Guaviare, especialmente, 
aunque en 2015 también en ellos hubo anulación de inscripciones, llegando por primera vez a todos de departamentos. En 2000 disminuyó el número de departamentos y de municipios, tal vez porque este año se tipificó la trashumancia electoral como delito y tuvo un impacto inmediato que luego desapareció. En cuanto al número de municipios, hay una tendencia creciente y después de 2000 se incrementó sustancialmente la anulación de inscripciones. ${ }^{5}$

Tabla 1. Departamentos y municipios con anulación de inscripción de cédulas por trashumancia.

\begin{tabular}{|c|c|c|}
\hline Año & Departamentos & Municipios \\
\hline 1994 & $27(84,3 \%)$ & $340(33,2 \%)$ \\
\hline 1997 & $28(87,5 \%)$ & $426(39,9 \%)$ \\
\hline 2000 & $21(65,6 \%)$ & $324(30,4 \%)$ \\
\hline 2003 & $30(93,7 \%)$ & $723(65,6 \%)$ \\
\hline 2007 & $30(93,7 \%)$ & $640(58,0 \%)$ \\
\hline 2011 & $28(87,5 \%)$ & $727(65,9 \%)$ \\
\hline 2015 & $32(100 \%)$ & $879(79,7 \%)$ \\
\hline
\end{tabular}

Fuente: elaboración propia a partir de Semana (1994, octubre 31); El Tiempo (1997, agosto 15; septiembre 13; 2000, octubre 26; 2003, agosto 23; 2007, octubre 17); Registraduría Nacional del Estado Civil (2011); Misión de Observación Electoral (2012; s. f.).

En términos absolutos, en las dos décadas analizadas hay un crecimiento exponencial de la anulación de inscripción de cédulas por trashumancia electoral, la cual pasó de 500000 en 1994 a 1276000 en las elecciones de 2015. Inicialmente el Consejo Nacional Electoral (CNE) anuló la inscripción de 1605109 cédulas, pero ante las reiteradas reclamaciones de políticos, asociaciones civiles y personas que demostraron que su cambio de residencia era verdadero se debieron habilitar 259000 cédulas, más otras 70000 validadas en Bogotá (véase gráfica 2).

\footnotetext{
${ }^{5}$ El número de municipios se ha incrementado. Entre 1994 había 1024 municipios, entre 1997 y 2000 aumentó a 1066, este último año hubo elecciones en 939 pues en 127 municipios hubo elecciones atípicas previamente. En las elecciones de 2003 había 1096; en 2007 había 1102; y entre 2011 y 2015 había 1103 municipios.
} 
Democracia electoral fraudulenta. La trashumancia electoral como estrategia...

Gráfica 2. Evolución de cancelación de inscripción de cédulas por trasteo electoral.

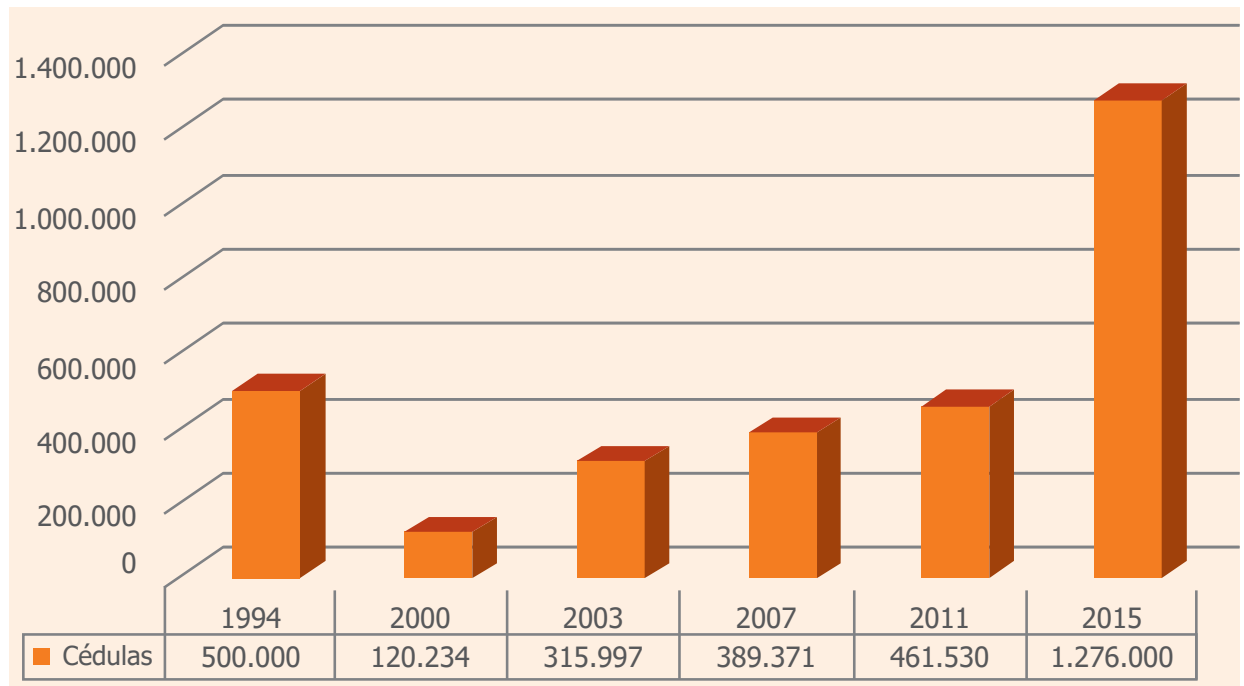

Fuente: elaboración propia a partir de El Tiempo (1997, agosto 15; 2000, octubre 30; 2007, octubre 17); Semana (1994, octubre 31; 2015, octubre 22b); Registraduría Nacional del Estado Civil (2011); El Espectador (2015, octubre 19).

Desde que hay datos confiables — de las elecciones locales de 1988, 1990 y 1991 no hay información sistemática - la cantidad de inscripciones de cédulas ha ido en aumento. En 1997 el entonces presidente (e) del CNE, Fernando Mayorga, declaró que «se habían trasteado a medio país» al dar cuenta de que en 426 de los 1066 municipios y en 28 de los 32 departamentos se anularon cédulas por esta práctica irregular e ilegal (El Tiempo, 1997, agosto 15). Pocos años después, en 2003, el fenómeno llegó a tal magnitud que el respectivo presidente de esta institución declaró: «La situación era escandalosa. Prácticamente hay trasteo en todo el país» (El Tiempo, 2003, agosto 23).

Una mirada detallada permite apreciar mejor el peso que tienen estos votantes foráneos en municipios pequeños, especialmente en los que tienen entre 50000 y 30000 habitantes - 119 municipios (10,6\%) - y los que tienen menos de 30000 habitantes —872 (77,7\%)—, en los que algunos cientos de votos definen una elección. En muchos de estos municipios la 
trashumancia se hace a «plena luz» y con la complicidad o anuencia de los funcionarios de las registradurías locales. En las elecciones de 2011, 95,7\% de las inscripciones anuladas se hicieron en municipios con menos de 30 000 habitantes —696 de los 727 municipios con trashumancia. En algunos municipios es tal la magnitud del acarreo electoral que resultan siendo más los votantes potenciales que los habitantes del poblado, así sucedió en 56 municipios en las elecciones de 2011 y en 96 localidades en 2015 (Semana, 2011, septiembre 22; MOE, s. f.).

Otra forma de cuantificar la trashumancia electoral es mediante la proporción de inscripción de cédulas anuladas que no corresponden al domicilio declarado de quien la inscribe. Se puede describir esta situación como una pirámide inversa: una base amplia en la que están las cédulas inscritas en cada ciclo electoral — que son las de nuevos electores que votan por primera vez, o los que nunca han votado y deben inscribirse para zonificarse, o los que cambiaron de lugar de residencia y quieren votar en este, o los que se inscriben en un lugar aun viviendo en otro-, las inscripciones revisadas por el CNE porque existen dudas y las inscripciones anuladas. Como se observa en la tabla 2, en las tres últimas elecciones de 2007, 2011 y 2015 aumentó la cantidad y el porcentaje de inscripciones anuladas hasta casi ajustar la tercera parte de los nuevos inscritos. Hay un amplio sector de electores dispuestos a transar económicamente con su voto, a lo cual habría que agregar a quienes ya lo hacen y son parte del censo electoral, además de aquellos que están incorporados a redes clientelares. En todo caso, son decenas de miles los votantes trasplantados.

Tabla 2. Revisión y anulación de cédulas inscritas en elecciones locales 2007-2015.

\begin{tabular}{|l|c|c|c|}
\hline \multicolumn{1}{|c|}{ Instancia } & $\mathbf{2 0 0 7}$ & $\mathbf{2 0 1 1}$ & $\mathbf{2 0 1 5}$ \\
\hline Cédulas nuevamente inscritas & 3662934 & 3909594 & 4212520 \\
\hline Inscripciones revisadas por el CNE & 961415 & 1078594 & 3803114 \\
\hline Porcentaje de inscripciones revisado & $26,2 \%$ & $27,6 \%$ & $90,3 \%$ \\
\hline Inscripciones anuladas & 389371 & 461530 & 1276000 \\
\hline Porcentajes de inscripciones anuladas & $10,6 \%$ & $11,8 \%$ & $30,2 \%$ \\
\hline
\end{tabular}

Fuente: elaboración propia a partir de MOE (s. f.). Datos de 2015 a partir de Semana (2015, octubre 22b). 
Pero las cifras no captan todo el fenómeno. Aunque en 2015 se llegó a una cifra récord de anulación de inscripción de cédulas por trashumancia electoral, hay una porción indeterminada de votantes foráneos que se camufla por reiteración. El entonces presidente del CNE, Felipe García, declaró que «no se logra eliminar toda la trashumancia porque hay una que es histórica, enquistada. En ciertos municipios esos traslados se han venido acumulando. Los buscan para cada elección y vuelven a pagarles» (El Universal, 2015, octubre 3).

En suma, los datos anteriores indican que se trata de una práctica muy extendida en centenares de municipios, aunque los votantes foráneos se concentran más en mercados electorales pequeños, en municipios con menos de 30000 habitantes en los que un puñado de votos puede decidir una elección. No obstante, se ha incrementado la capacidad de las agencias de control y de la organización electoral para enfrentar la trashumancia mediante la cancelación de inscripciones de cédulas.

\section{Conclusiones. Democracia electoral fraudulenta}

Como se ha argumentado a lo largo del artículo, el trasplante de votos se presenta por la conjugación de ciertas reglas permisivas para la creación de partidos políticos y para las candidaturas, la débil institucionalización organizativa de los partidos, el predominio de intermediación partidista clientelar y la prevalencia de una clase política del tipo políticos de negocios. A partir de estos factores habría que esbozar un esquema explicativo.

Es claro que la posibilidad de que ocurra un fraude debe ser baja si ningún partido y ningún político están interesados en cometerlo, si todos compiten de forma limpia y están suficientemente bien organizados, si cuentan con reglas claras de comportamiento en su interior, si controlan a sus integrantes y a sus facciones internas. Aunque compiten bajo las mismas reglas de juego - las cuales se han ajustado y son más exigentes-, los partidos actúan de forma diferente, lo cual depende de su estructura y del tipo de políticos que albergan.

Como se vio en los apartados anteriores, en Colombia hay numerosas normas tendientes a evitar y a sancionar la trashumancia electoral, y las autoridades electorales son cada vez más eficientes en la anulación de inscripciones de cédulas al verificar la no correspondencia con el lugar de 
residencia de las personas. La conformación y actualización de bases de datos permite el cruce con las inscripciones y han ido ganando en eficiencia y capacidad técnica, lo que se refleja en el número creciente de inscripciones fraudulentas que son anuladas. No obstante, la justicia falla, y a pesar de la abundancia de normas y la creación del nuevo tipo penal de fraude electoral son muy pocos los condenados. Resulta difícil demostrar el delito, solo cuando se descubre que hay retención de cédulas por los mochileros, líderes o capitanes —incluso por los mismos políticos-, o se descubren altas sumas de dinero el día de las elecciones en manos de algunas personas que hacen parte de la trama de movilización y traslado de electores.

También son muy pocos los casos en que se han anulado elecciones a causa de esta manipulación de los votantes trasplantados. ${ }^{6}$ Además de las altas exigencias para la aceptación de pruebas y del cruce de las bases de datos que indica la residencia de la persona, se requiere: a) que se demuestre que no hay un vínculo indicativo de pertenencia de la persona con el municipio; b) que los inscritos de forma irregular votaron en las elecciones; y más difícil aún, c) que se demuestre la efectividad del votos, es decir, que incluso demostrando que hubo votantes trasplantados, se verifique que los votos irregulares decidieron el resultado final, de lo contrario, la nulidad del voto resulta inocua.

Por lo descrito en este artículo cabe plantear si a los adjetivos con que suele denominarse la democracia colombiana que incluyen los de semidemocracia, régimen ambiguo, democracia disfuncional, democracia defectuosa y democracia precaria, se puede adicionar el de democracia electoral fraudulenta, una democracia con adjetivos negativos que en su dimensión electoral presenta como uno de sus atributos centrales el fraude y las urnas contaminadas.

\section{Referencias bibliográficas}

1. Basedau, Matthias \& Stroh, Alexander. (2008). Measuring Party Institutionalization in Developing Countries: A New Research Instrument Applied to 28 African Political Parties. GIGA Working Papers, 69. https://doi.org/10.2139/ssrn.1119203

\footnotetext{
${ }^{6}$ Se han realizado 10 elecciones de alcaldes desde 1988 -más de 8000 alcaldes—, 8 elecciones para Gobernación —236 gobernadores-, además de 10 elecciones de concejales —10 000 en cada elección - y diputados — cerca de 400 en cada elección—. En conjunto, se pudieron documentar solo 17 anulaciones de elecciones por comprobada trashumancia electoral.
} 
2. Cante, Fredy. (2011). ¿Son libres los votantes en Colombia? Desafíos, 23 (1), pp. 15-55.

3. Caracol Radio. (2007, septiembre 3). Registraduría nacional designa 530 mil jurados para elecciones de octubre. Recuperado de http://caracol.com.co/ radio/2007/09/03/nacional/1188837180_475174.html

4. Crespo, José Antonio. (2013). Elecciones y democracia. México, D. F.: Instituto Federal Electoral.

5. Colombia. Asamblea Nacional Constituyente. Constitución Política. (20 de julio de 1991). Recuperado de http://www.secretariasenado.gov.co/senado/basedoc/ constitucion_politica_1991.html

6. Colombia. Congreso de la República. Ley 6. (5 de enero de 1990). Por la cual se reforma el Decreto 2241 de 1986 (Código Electoral) y se dictan otras disposiciones. Recuperado de http://www.funcionpublica.gov.co/eva/gestornormativo/norma. php?i $=9028$

7. Colombia. Congreso de la República. Ley 163. (31 de agosto de 1994). Por la cual se expiden algunas disposiciones en materia electoral. Recuperado de http:// www.secretariasenado.gov.co/senado/basedoc/ley_0163_1994.html

8. Colombia. Congreso de la República. Ley 599. (24 de julio de 2000). Por la cual se expide el Código Penal. Recuperado de http://www.secretariasenado.gov.co/ senado/basedoc/ley_0599_2000.html

9. Colombia. Consejo Nacional Electoral. Resolución 0215. (22 de marzo de 2007). Por la cual se establece el procedimiento breve y sumario a seguir para dejar sin efecto la inscripción irregular de cédulas. Recuperado de https://www.registraduria. gov.co/IMG/pdf/res_0215_2007.pdf

10. Colombia. Corte Constitucional. Sentencia T-135. (17 de febrero de 2000). Recuperado de http://www.corteconstitucional.gov.co/relatoria/2000/T-135-00.htm

11. Cox, Gary W. \& Thies, Michael F. (2000). How Much Does Money Matter? «Buying Votes» in Japan, 1967-1990. Comparative Political Studies, 33 (1), pp.37-57. https://doi.org/10.1177/0010414000033001002

12. Della Porta, Donatella. (1996). Partidos políticos y corrupción. Reflexiones sobre el caso italiano. Nueva Sociedad, 145, pp. 92-109.

13. Duarte García, Ricardo. (1994). El Mercado político y la lógica de la clientela. Revista Foro, 23, pp. 17-25.

14. Duque, Javier. (2005). La institucionalización partidista. Una propuesta de abordaje de las estructuras organizativas partidistas. Estudios Políticos, 27, pp. 103-127.

15. Duque, Javier. (2018). Las urnas contaminadas. Elecciones, fraude y manipulación en la democracia colombiana 1990-2015. La Carreta: Medellín.

16. El Espectador. (2015, octubre 19). Reversazo del Consejo Nacional Electoral en anulación de inscripción de cédulas en Bogotá. Recuperado de https:// www.elespectador.com/noticias/politica/reversazo-del-consejo-nacional-electoralanulacion-de-i-articulo-593622 
17. El Heraldo. (2015, septiembre 20). Cómo funciona la cadena de trashumancia y la compra de votos. Recuperado de https://www.elheraldo.co/politica/como-operala-cadena-de-la-trashumancia-y-la-compra-de-votos-218349

18. El Tiempo. (1997, agosto 15). Según CNE, se habría trasteado a medio país. Recuperado de https://www.eltiempo.com/archivo/documento/MAM-620808

19. El Tiempo. (1997, septiembre 13). Anulan inscripción de 2.000 cédulas. Recuperado de https://www.eltiempo.com/archivo/documento/MAM-644154

20. El Tiempo. (2000, octubre 26). Hay 120.234 cédulas castigadas para votar. Recuperado de https://www.eltiempo.com/archivo/documento/MAM-1267688

21. El Tiempo. (2000, octubre 30). 109 capturas por delitos electorales. Recuperado de https://www.eltiempo.com/archivo/documento/MAM-1265475

22. El Tiempo. (2002, abril 13). Así fue el fraude electoral. Recuperado de https:// www.eltiempo.com/archivo/documento/MAM-1377169

23. El Tiempo. (2003, agosto 23). Descubren gran fraude preelectoral. Recuperado de https://www.eltiempo.com/archivo/documento/MAM-1033936

24. El Tiempo. (2007, octubre 17). Aumentó trasteo de votantes: anularon 373.467 inscripciones de cédulas. Recuperado de https://www.eltiempo.com/archivo/ documento/MAM-2693588

25. El Tiempo. (2011, octubre 4). Empiezan a reemplazar a registradores investigados. Recuperado de https://www.eltiempo.com/archivo/documento/MAM4872101

26. El Tiempo. (2015, octubre 8). Registrador y candidata, detenidos por irregularidades electorales. Recuperado de https:/www.eltiempo.com/archivo/ documento/CMS-16398195

27. El Universal. (2015, octubre 3). «Hay una trashumancia histórica enquistada en los municipios». Recuperado de http://www.eluniversal.com.co/elecciones/2015/ noticias/hay-una-trashumancia-historica-enquistada-en-los-municipios-162

28. El Universal. (2015, octubre 23). Capturado registrador de Lórica por presuntos vínculos con cartel de trasteo. Recuperado de https://www.eluniversal. com.co/regional/cordoba/capturado-registrador-e-de-lorica-por-presuntos-vinculoscon-cartel-de-trasteo-ESEU311775

29. Fiscalía General de la Nación. (2015, octubre 9). Capturan a candidato a la Alcaldía de San Fernando (Bolívar) por fraude electoral. Boletín de Prensa, 12094. Recuperado de https://www.fiscalia.gov.co/colombia/noticias/capturan-a-candidato-ala-alcaldia-de-san-fernando-bolivar-por-fraude-electoral/

30. Fiscalía General de la Nación. (2015, octubre 14). Por fraudes electorales en Atlántico, capturada registradora de Puerto Asís. Boletín de Prensa, 12117. Recuperado de https://www.fiscalia.gov.co/colombia/noticias/por-fraudes-electoralesen-atlantico-capturada-registradora-de-puerto-asis/

31. Fiscalía General de la Nación. (2015, octubre 16). Juicio por intento de fraude electoral en elecciones atípicas del 2011 en Valle del Cauca. Boletín de Prensa, 12131. 
Recuperado de https://www.fiscalia.gov.co/colombia/noticias/juicio-por-intento-defraude-electoral-en-elecciones-atipicas-del-2011-en-valle-del-caucal

32. Fiscalía General de la Nación. (2015, octubre 26). Boletín de Prensa, 12253. Recuperado de https://www.fiscalia.gov.co/colombia/noticias/asegurado-registradormunicipal-de-atrato-choco/

33. Fiscalía General de la Nación. (2015, diciembre 2). Capturado por fraude en escrutinios de Barranquilla. Boletín de Prensa, 12678. Recuperado de https://www. fiscalia.gov.co/colombia/noticias/capturado-por-fraude-en-escrutinios-de-barranquilla/

34. Gutiérrez Sanín, Francisco. (1998). Clientelismo y sus enredos. En: La ciudad representada: política y conflicto en Bogotá (pp. 55-120). Bogotá, D. C.: TM.

35. Katz, Richard y Mair, Peter. (1990, 9-13 de julio). Three Faces of Party Organization: Adaptation and Change. XII Congreso Mundial de Sociología. Universidad Complutense de Madrid, Madrid.

36. Leal, Francisco y Dávila, Andrés. (1990). Clientelismo: el sistema Político y su expresión regional. Bogotá, D. C.: IEPRI-UNAL.

37. Lehoucq, Fabrice. (2007). ¿Qué es el fraude electoral? Su naturaleza, sus causas y consecuencias. Revista Mexicana de Sociología, 69 (1), pp. 1-38.

38. León M., Alfredo Antonio. (2011). Penumbras y demonios en la política colombiana: un análisis sobre el clientelismo. Bogotá, D. C.: Desde Abajo.

39. Llanos Rodado, Roberto. (2001, abril 17). Detención a 4 registradores. El Tiempo. Recuperado de https://www.eltiempo.com/archivo/documento/MAM437420

40. Martz, John D. (1997). The Politics of Clientelism: Democracy \& the State in Colombia. New Brunswick: Transaction.

41. Misión de Observación Electoral (MOE). (2012). Análisis de trashumancia electoral de 2011. Bogotá, D. C.: MOE.

42. Misión de Observación Electoral (MOE). (s. f.). Inscripción y anulación de cédulas en las elecciones de autoridades locales de 2015. Recuperado de https://moe. org.co/home/doc/moe_nacional/8\%20Informe $\% 20 \mathrm{de} \% 20$ Inscripci $\%$ F 3n $\% 20 y \% 20$ anulaci $\%$ F3n $\% 20$ de $\%$ 20c\%E9dulas $\% 20$ ( + censo).pdf

43. Pachón, Mónica. (2018). Recomendaciones para mejorar la representación política y disminuir los incentivos al abuso del poder político. Fedesarrollo. Recuperado de https://www.repository.fedesarrollo.org.co/bitstream/handle/11445/3548/Pachon_ Abril_2018_Recomendaciones.pdf?sequence $=1$ \&isAllowed $=y$

44. Pérez Mier, Tonny. (1998, mayo 22). No me corrompan a los funcionarios: Registrador. El Tiempo. Recuperado de https:/www.eltiempo.com/archivo/ documento/MAM-754388

45. Registraduría Nacional del Estado Civil. (2011). Inscripción de cédulas y mapa de riesgo de trashumancia electoral. Nuestra Huella, 49.

46. Rubio, Rocío. (2003). No hay paraísos sino los perdidos: historia de una red clientelista en Bogotá. Bogotá, D. C.: Universidad Nacional de Colombia. 
47. Schedler, Andreas. (2013). The Politics of Uncertainty: Sustaining and Subverting Electoral Authoritarianism. London: Oxford University. https://doi. org/10.1093/acprof:oso/9780199680320.001.0001

48. Semana. (1994, octubre 31). Votos Errantes. Recuperado de https://www. semana.com/nacion/articulo/votos-errantes/23928-3

49. Semana. (2009, noviembre 21). Votos por los cielos. Recuperado de https:// www.semana.com/nacion/articulo/votos-cielos/110126-3

50. Semana. (2011, septiembre 22). CNE encontró municipios donde el censo electoral es mayor a la población. Recuperado de https://www.semana.com/nacion/ articulo/cne-encontro-municipios-donde-censo-electoral-mayor-poblacion/246807-3

51. Semana. (2015, octubre 22a). Los cinco funcionarios de la Registraduría capturados en menos de 24 horas. Recuperado de https://www.semana.com/ nacion/articulo/los-funcionarios-de-la-registraduria-capturados-en-menos-de-24horas/447059-3

52. Semana. (2015, octubre 22b). CNE vuelve a reversar decisión sobre cédulas anuladas. Recuperado de https://www.semana.com/nacion/articulo/250000-personaspodran-votar-donde-inscribieron-su-cedula-para-elecciones/447090-3

53. Sierra Palencia, Paola. (2013, diciembre 22) Anatomía de la compra de votos en Barranquilla. El Heraldo. Recuperado de https://www.elheraldo.co/local/anatomiade-la-compra-de-votos-en-barranquilla-136830

54. Yardimci-Geyikci, Sebnem. (2013). Party Institutionalization and Democratic

[ 86 ] Consolidation: Turkey and Southern Europe in Comparative Perspective. Party Politics, 21 (4), pp. 527-538. https://doi.org/10.1177/1354068813487110 